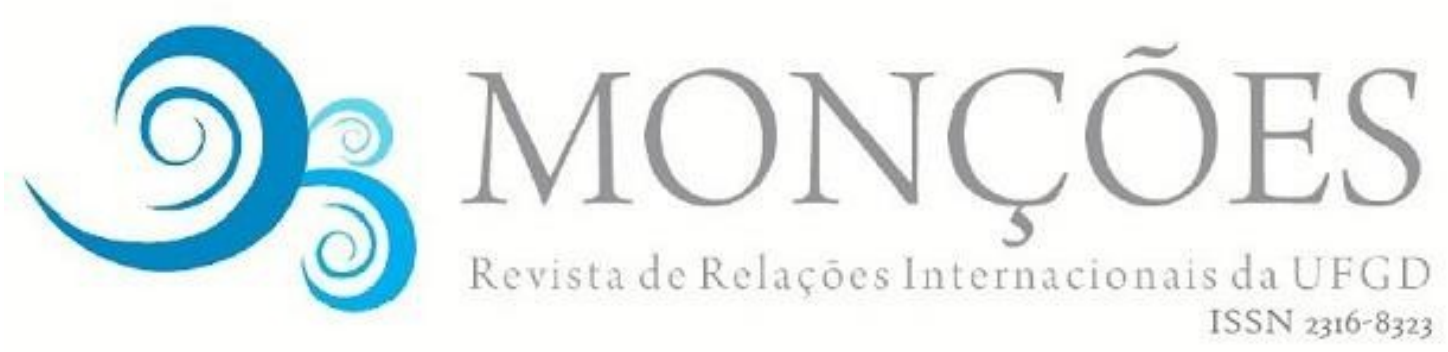

\title{
CIDADANIA GLOBAL E DIREITOS HUMANOS: EFEITOS EDUCACIONAIS DO DESENVOLVIMENTO DE SIMULAÇÃO DA ONU NO VALE DO JEQUITINHONHA
}

\begin{abstract}
ALEX LARA MARTINS
Professor Doutor do Instituto Federal do Norte de Minas Gerais, Campus Almenara.
\end{abstract}

ALFREDO COSTA

Professor Doutor do Instituto Federal do Norte de Minas Gerais, Campus Almenara.

LEONARDO MACHADO PALHARES

Diretor de Ensino do Instituto Federal do Norte de Minas Gerais, Campus Almenara, e doutorando em História pela Universidade de Évora.

\begin{abstract}
RESUMO: O objetivo do artigo é identificar o nível de compreensão e engajamento dos estudantes de nível médio sobre temas relacionados aos Direitos Humanos, resultantes da experiência políticopedagógica de simulação de comitês da Organização das Nações Unidas (ONU). Este projeto está em consonância com os programas da ONU de disseminação de pautas relacionadas aos Direitos Humanos. O estudo ambientou-se durante o projeto de ensino IFMUNDO, realizado em uma instituição de ensino do Vale do Jequitinhonha. Buscou-se evidenciar de forma descritiva o conhecimento dos estudantes acerca dos temas propostos, desenvolvendo uma abordagem quantitativa, por meio da análise de uma amostra da população total dos estudantes dos cursos de Ensino Médio. $O$ instrumento de pesquisa utilizado foi o questionário estruturado, com a escolha do método de coleta de dados. A aplicação do questionário deu-se em duas campanhas, antes e após a culminância do evento. Conclui-se que este instrumento pedagógico é capaz de disseminar a consciência de cidadania global e de potencializar competências e habilidades que respondam aos desafios para a efetivação dos Direitos Humanos.
\end{abstract}

PALAVRAS-CHAVE: Direitos Humanos. Pedagogia de Simulação. IFMUNDO.

GLOBAL CITIZENSHIP AND HUMAN RIGHTS: EDUCATIONAL EFFECTS OF A UNITED NATIONS SIMULATION IN THE JEQUITINHONHA VALLEY (MINAS GERAIS, BRAZIL)

ABSTRACT: The aim of the paper is to identify the level of understanding and engagement of middle school students on human rights issues, based in its experience at a political-pedagogical practice of simulation of the United Nation committees. This project stands by the UN guidelines for Human Rights worldwide diffusion. The study took place during the IFMUNDO project, held at an education 
institution in the Jequitinhonha Valley, Brazil. Its main purpose is to provide descriptive evidences of the middle school student's knowledge level variation about the UN themes, through a quantitative approach using a structured questionnaire, which was applied in two campaigns, before and after the conclusion of the experience. It is concluded that the UN Simulation practice as a pedagogical tool is capable to disseminate the awareness of global citizenship and to increase skills and abilities that responds to the challenges for the diffusion of Human Rights.

KEYWORDS: Human Rights. Simulation Pedagogy. IFMUNDO.

\section{Introdução}

Em cumprimento ao plano de ação desenvolvido durante a Conferência Mundial sobre os Direitos Humanos (2004), a Organização das Nações Unidas (ONU) estabeleceu o Programa Mundial para a Educação em Direitos Humanos (World Programme for Human Rights Education), dividido em três fases de implantação. Durante a primeira fase (2005-2009), criaram-se estratégias pedagógicas relacionadas aos Direitos Humanos que pudessem ser adotadas pelos sistemas de ensino dos níveis fundamental e médio - no Brasil denominado Educação Básica. Na segunda fase (2010-2014), instituíram-se programas de treinamento para professores e estudantes de cursos de graduação (licenciaturas, bacharelados e tecnólogos), para membros da sociedade civil e oficiais do governo. A terceira fase do programa (2015-2019) está criando recursos de treinamento para os profissionais da mídia e fomentando editoriais de revistas científicas, de modo a potencializar a divulgação dos resultados obtidos nas fases anteriores (UNGA, 2004, 2005). Além de formar profissionais preparados para disseminar o conhecimento sobre as temáticas relacionadas aos Direitos Humanos e de produzir material bibliográfico de apoio, o Programa induziu as instituições de ensino a criarem mecanismos capazes de efetivar a sua agenda, seja por meio da atualização dos currículos, seja através da criação de ferramentas pedagógicas específicas.

Um dos instrumentos político-pedagógicos utilizado para disseminar valores e conceitos consoantes aos Direitos Humanos é a pedagogia de simulação de organizações, que consiste em simular o funcionamento de agências, organismos e instituições nacionais e internacionais, com os objetivos de promover e vivenciar práticas parlamentares, de discutir e debater ideias em ambiente público, de promover o desenvolvimento acadêmico, a percepção geopolítica e o engajamento 
dos participantes em problemáticas globais. As simulações podem ocorrer em ambiente competitivo, em que os times concorrentes testam as suas habilidades para resolver questões de ordem jurídica, como a competição Jean Pictet (LANORD; DEYRA, 1995), ou em ambiente colaborativo, em que o grupo busca uma solução comum, que beneficie ao máximo os membros envolvidos pela situação.

As atividades dos modelos de simulação pautam-se pelas orientações da Organização das Nações Unidas para a Educação, a Ciência e a Cultura (UNESCO), que promove a cultura da paz, da democracia e da cooperação mundial através do fortalecimento da educação escolar (SHULTZ; GUIMARÃES-IOSIF, 2009; MARUM, 2016). Esses aspectos foram reforçados pela conferência Rio-92 e pela Agenda 21, sob a perspectiva da sustentabilidade econômica e ambiental (FREIRE, 2007). Baseiam-se, também, nos princípios elencados pela Agenda Educação 2030, especialmente o Objetivo 4, que prevê a garantia fundamental da educação enquanto um direito humano e um bem público instituidor da paz, da diversidade cultural, do desenvolvimento sustentável e das igualdades sociais e de gênero (ONU, 2015, p. 6).

Reiteradas vezes a ONU apontou e reforçou a necessidade do desenvolvimento de ações de aprimoramento do fazer educacional capazes de contribuir para ampliar a capacidade de transformação das realidades locais, regionais e nacionais por meio de iniciativas da própria comunidade escolar. Nesta perspectiva, Dowbor (2009) evidencia que a promoção de uma educação voltada ao desenvolvimento local pressupõe educadores que não forneçam apenas o conjunto básico de conhecimentos do ementário escolar, mas educadores que transcendam e articulem as necessidades do próprio local e os conhecimentos correspondentes para supri-las. Por consequência, eles atuariam para transformar a condição do educando, de mero espectador passivo que adquire informações, para alguém que desenvolva a capacidade de agente da transformação social no meio em que vive. Para torná-lo possível, a UNESCO propõe a implementação nas escolas da Educação para a Cidadania Global (ECG). Esta metodologia busca desenvolver nos estudantes - a partir de suas habilidades cognitivas, socioemocionais e comportamentais - sentimentos e percepções vinculados à noção de pertencimento a uma comunidade que supera as fronteiras nacionais e que traz a noção humanidade como fundamento comum a todos os indivíduos (UNESCO, 2016a). 
Os cidadãos globais são definidos pela UNESCO como aqueles indivíduos capazes de pensar e agir visando a promoção de um mundo mais justo, pacífico e sustentável, com respeito aos direitos humanos, à justiça social, à diversidade, à igualdade de gênero e à sustentabilidade ambiental (UNESCO, 2016b). A sua formação é facilitada pela existência de um ambiente aberto aos valores universais e pela prática de pedagogias transformadoras (UNESCO, 2015).

Freire (2007) esclarece que a preparação dos estudantes para uma sociedade global exige a mudança do paradigma escolar de maneira que se possa associar as pesquisas às práticas letivas. Também chama a atenção para a necessidade de se formar e aperfeiçoar professores tornando-os capazes de compreender as próprias práticas educacionais, o que os habilitaria a atuar para que os educandos reconheçam as diferentes maneiras pelas quais o desenvolvimento local pode ter efeitos globais e, ao mesmo tempo, para que resistam aos efeitos da globalização massificada em suas vidas. O filósofo Edgar Morin (2015, p. 201) defende que uma reforma do sistema educacional que responda às complexas questões contemporâneas depende de uma reforma preliminar do pensamento, em que os sujeitos deixem de ser reprodutores de informação. Neste contexto, aceita-se o desafio de superação definido por Marum (2016) como aquele de maior relevância atual, qual seja, o de ressignificar o espaço escolar e as relações de aprendizagem.

Os modelos de simulação da ONU apresentam-se como metodologias de vanguarda para alcançar esse objetivo, pois abrangem tanto a reflexão sobre temas que preocupam a população global, quanto sobre o modo pelo qual políticas globais interferem em questões regionais. Estimula-se, ainda, a solidariedade, o respeito e a empatia em relação a outros povos, com foco na dicotomia sociológica entre minorias e maiorias, e nos conceitos de alteridade e educação para a diversidade. $O$ contato com essas temáticas pode ser facilitado pela promoção de atividades e vivências pedagógicas inter e transdisciplinares que contribuam para o aprimoramento da capacidade cognitiva dos estudantes, incluindo habilidades para organização e exposição das suas ideias.

Com a intenção de implementar as práticas pedagógicas convergentes com - Programa da ONU, capazes de promover os quatro pilares definidos pela UNESCO para uma educação de qualidade (aprender a ser, aprender a aprender, aprender a fazer e aprender a conviver juntos), promoveu-se no Instituto Federal do 
Norte de Minas Gerais (IFNMG) - Almenara, Vale do Jequitinhonha - um projeto de ensino de simulação de comitês da ONU denominado IFMUNDO, que abrange a formação da cidadania global, a inclusão e a justiça social, o reconhecimento das riquezas e identidades culturais. As temáticas deste projeto de ensino incorporam o papel da ONU na resolução dos problemas mundiais, bem como a importância dos direitos humanos, a democracia e tolerância, a aprendizagem intercultural, e o meio ambiente e desenvolvimento sustentável, que são eixos norteadores do projeto.

Assim, este artigo apresenta o resultado da investigação sobre os impactos positivos e negativos na percepção de conhecimento dos estudantes do ensino médio a respeito dos cinco temas-alvo do modelo de simulação: questões gerais sobre o modelo, conhecimentos específicos sobre os comitês da ONU, percepção sobre conflitos internacionais e papel da ONU, engajamento do estudante em relação ao evento e percepção sobre o envolvimento da comunidade escolar.

Essa pesquisa aponta um dos caminhos para suprir a lacuna1 nos estudos acerca das metodologias de ensino e processos de conhecimento científico no campo da pedagogia das simulações organizacionais, especialmente no que diz respeito ao público concluinte do Ensino Básico. Em conformidade com a metodologia de McAvoy \& Hess (2013), far-se-á o exame, por meio do modelo de pesquisa descritivo-explicativa, de quanto a simulação de organização da ONU pode criar um ambiente em que os jovens possam se engajar em atividades que envolvam reflexão e modificação social e política, especialmente na microrregião do Baixo Jequitinhonha - área de abrangência do IFNMG Campus Almenara.

\section{Referencial Teórico}

O pressuposto da ECG é que a construção dos saberes escolares deve romper com os modelos bancários e fragmentados. Os saberes têm que ser trabalhados dentro de um contexto significativo e integrados por meio de

\footnotetext{
${ }^{1}$ O levantamento bibliográfico realizado revelou uma série de publicações de relatos de experiência e de avaliações qualitativas do desempenho da metodologia de simulação de comitês da ONU, sem, contudo, imersão sistemática quantitativa capaz de traduzir em números a eficácia da metodologia. Exceção para Valadares Vasconcelos (2015), que descreve os impactos dos procedimentos metodológicos do Concurso Nacional Sistemas Interamericano e Internacional de Direitos Humanos (CNSIDH). É esta a lacuna que se busca preencher aqui.
} 
projetos/temas interdisciplinares. A escola, por exemplo, lida com indivíduos cujas histórias são heterogêneas, podendo sofrer interferências do contexto socioeconômico e das condições fisiológicas e psicológicas. Nesse caso, o que podemos fazer é buscar por pedagogias transformadoras e alternativas metodológicas que permitam aos estudantes a apropriação da realidade e a solução de problemas. Isso significa a concessão de procedimentos capazes de desenvolver a capacidade do estudante de usar os seus recursos cognitivos e os seus conhecimentos para dar respostas a situações variadas.

Por meio da ECG, o educando tem a oportunidade de se envolver em atividades cujo objetivo é a resolução de problemas e a superação de obstáculos. Essa estratégia didática parte do princípio de que um problema é "uma situação que um indivíduo ou grupo quer ou precisa resolver e para a qual não dispõe de um caminho rápido e direto que o leve à solução" (LESTER, 1983 apud POZO, 1998, p. 15). Para ser competente quanto à capacidade de superar os obstáculos, ele deve ser capaz de manipular as seguintes habilidades:

- Escolher o tipo de procedimento mais adequado, considerando as características da situação;

- Aplicar seus conhecimentos na busca de soluções para problemas concretos;

- Progredir, sucessivamente, em suas aprendizagens;

- Elaborar estratégias ou se apropriar de procedimentos necessários à construção de respostas;

- Elaborar novas ideias e desenvolver habilidades diversificadas de acordo com o tipo de problema;

- Construir estratégias de resolução para uso em novas situaçõesproblema.

Em uma situação-problema, o objetivo pedagógico principal encontra-se no obstáculo a ser vencido e não na tarefa propriamente dita. Por essa razão, o problema deve ser elaborado a partir das possibilidades cognitivas dos estudantes e dos objetivos que se quer alcançar. 
Nos modelos de simulação da ONU são apresentadas situações-problema mundiais contemporâneos, o que exige que cada estudante pense sua resolução sob a perspectiva socioeconômica e cultural do país que representa. Em seguida, espera-se que eles construam, a partir do diálogo, soluções que atendam às partes e aos interesses múltiplos do debate. Vislumbra-se, assim, a construção de educação pelo e para o diálogo. Mas, o que é o diálogo? O físico David Bohm (2011) o definiu como um movimento em que o indivíduo discorre, sem medo, sobre uma ideia, um conceito ou um interesse. O diálogo é movido, portanto, pela crença que o "eu" só existe na relação aberta com o "outro". Esta definição pressupõe que o diálogo é o princípio máximo da convivência entre os povos, por isso ele também é o princípio orientador das simulações.

A resolução das situações-problema deve levar em consideração os conhecimentos prévios que os estudantes trazem. As concepções prévias, mesmo que não tenham âncora em hipóteses cientificamente testadas, devem ser vistas como momentos particulares no processo de reconstrução do conhecimento. É por meio delas que o educando entra em contato com o problema proposto e questiona tanto os seus conhecimentos prévios quanto o conteúdo formal ao qual fora exposto. No caso das simulações da ONU, observa-se a ampliação do conjunto de tais questionamentos, pois, ao representar determinadas culturas ou perspectivas sociais, exige-se o reconhecimento das diferenças e o desenvolvimento da capacidade de observar o mundo como "o outro". Não é incomum que, ao longo desse exercício, as novas perspectivas absorvidas entrem em conflito com as suas construções sociais anteriores.

Concebida dessa forma, as situações-problema parecem responder a alguns desafios que constituem o ensino na atualidade, compondo diferentes funções:

- A função motivadora, que gera a vontade de aprender diante do enigma apresentado; mobiliza o pensamento do estudante na busca de soluções;

- A função didática, que tem como objetivo a apropriação de diversos saberes; possibilita a integração dos conteúdos; 
- A função emancipadora, que constitui um espaço de elaboração e reelaboração de procedimentos eficazes à resolução dos problemas propostos.

Essa forma de desenvolver os conteúdos pode acontecer em várias situações de aprendizagem. Em alguns momentos, os estudantes são convidados a buscar soluções para um problema usando de seus próprios recursos cognitivos. Em outros momentos, a situação-problema é proposta para um grupo de estudantes, de forma que a solução seja uma busca coletiva que possibilite a troca de conhecimentos e experiências. Nesta perspectiva, entende-se que

(...) o caminho do conhecimento implica busca e aprofundamento das relações que seja possível estabelecer em torno de um tema, relações tanto procedimentais como disciplinares; mas também do desenvolvimento da capacidade de propor-se problemas, de aprender a utilizar fontes de informações contrapostas ou complementares, e saber que todo ponto de chegada constitui em si um novo ponto de partida (Hernández, 1998, p. 48).

Uma das hipóteses deste trabalho é que as atividades de simulação de comitês da ONU respondem satisfatoriamente aos desafios da ECG. Os modelos de organização são instrumentos político-pedagógicos que tratam de questões locais, regionais, nacionais ou globais através da simulação do funcionamento de organismos, agências, instituições e governos. Trata-se de um grande jogo de interpretação de papéis (Role-playing game) organizado a partir de comitês, cujos participantes representam uma posição política específica, debatendo e negociando, dentro de uma arena controlada, questões globalmente relevantes. Estudos de caso mostram que essas experiências de simulação majoram o interesse político e o sentimento de cidadania entre os participantes, isto é, a noção de que o indivíduo deve participar ativamente das mudanças sociais (MCAVOY; HESS, 2013).

Os modelos de simulação da ONU são os mais disseminados no mundo. A pedagogia da simulação gerencial surgiu no final da década de 1950, como uma maneira de compreender e praticar a realidade das organizações gerenciais. De início, essa proposta pedagógica foi implementada nos cursos de administração de empresas. Desde então as próprias associações internacionais desenvolvem pesquisas e simulações sobre o seu próprio funcionamento. No Brasil, o estímulo do Ministério da Educação a novas metodologias de ensino e aprendizagem nos cursos 
de ensino superior, durante a década de 1990, incitou o crescimento do número de simulações organizacionais (DE PAULA et al., 2011). Além disso, o próprio Programa Mundial para a Educação em Direitos Humanos da ONU fomentou projetos deste tipo, com o Programa de Escolas Associadas vinculadas à UNESCO.

Embora sejam predominantes em escolas onde os estudantes possuem maior poder aquisitivo, estes programas têm conquistado a adesão de escolas em locais periféricos (LEVY, 2016). De acordo com Teixeira \& Teixeira (1998), esses programas possibilitam aos participantes exercitar habilidades relacionadas à solução de problemas e competências relacionadas ao autodesenvolvimento. Como instrumento pedagógico, pode servir como forma de inclusão sócio-política, de modo a frutificar entre os estudantes a mentalidade cooperativa, que vise a paz, promova os direitos humanos e auxilie no desenvolvimento social, através de práticas sustentáveis (ONU, 2015). Os comitês simulados durante o IFMUNDO foram os seguintes:

1. Organização das Nações Unidas para a Alimentação e a Agricultura (FAO), cujas questões fundamentais foram a erradicação da fome e a insegurança alimentar. Essa agência trabalhou de maneira coordenada com a Organização Mundial da Saúde (OMS). O tema gerador deste comitê conjunto foi Impactos do uso de Transgênicos e Agrotóxicos.

2. Organização das Nações Unidas para a Educação, a Ciência e a Cultura (UNESCO). Tendo em vista a disparidade entre as políticas socioeducacionais entre os países desenvolvidos e em desenvolvimento, simulou-se o tema proposto por essa agência em 2016: Inovação e internacionalização da Educação.

3. Programa das Nações Unidas para o Meio Ambiente (PNUMA), órgão vinculado à ONU Meio Ambiente, responsável por promover a conservação do meio ambiente e o uso eficiente de recursos no contexto do desenvolvimento sustentável. Considerando o sexto Objetivo da Agenda 2030, que versa sobre a disponibilidade e gestão sustentável da água e saneamento para todas e todos, este comitê discutiu as formas de uso sustentável e eficiente da água, a partir do tema Água potável e saneamento. 
4. Organização Mundial do Turismo (OMT), que é responsável por liderar e promover o Ano Internacional de Turismo Sustentável para o Desenvolvimento, a partir dos três pilares da sustentabilidade - econômico, social e ambiental. O comitê da OMT liderou a iniciativa no Sistema ONU, promovendo maior conscientização sobre os patrimônios cultural e ambiental das diversas civilizações.

5. Organização Mundial do Comércio (OMC), que define regras globais de comércio, com os princípios da concorrência leal e do tratamento diferenciado a países em desenvolvimento. Este comitê trabalhou conjuntamente com a Organização Internacional do Trabalho (OIT) para discutir, desenvolver e implementar políticas coerentes dentro do tema Igualdade de gênero no trabalho.

6. Conselho de Segurança das Nações Unidas (CSNU), que zela pela manutenção da paz e segurança dos países, cujas resoluções podem ser impositivas ou recomendativas. A Anistia Internacional vem pressionando, desde 2014, os governos de todo o mundo a pactuarem com o Tratado Internacional Sobre o Comércio de Armas. Por isso, o tema do comitê foi Controle de Armas.

O quadro 1 traz uma relação dos dez mais relevantes modelos de simulação da ONU no Brasil $^{2}$, segundo critérios de antiguidade, abrangência, número de comitês e tamanho do público atendido. Verifica-se que a maior parte deles acontece na região sudeste (06), e que duram entre quatro e cinco dias. Possuem média de 390 participantes, sendo a MiniONU a simulação de maior vulto, com média de mil participantes, seguida pela PoliONU, com 600. De modo geral, as simulações atendem aos níveis médio e superior, e possuem média de nove comitês, com destaque para MiniONU (20) e PoliONU (12) a mais antiga das simulações é a Americas Model United Nations (AMUN), com primeira edição em 1998, e a mais nova é a São Paulo Model United Nations (SPMUN), em atividade desde 2009.

\footnotetext{
${ }^{2}$ A consulta ao verbete "Modelo de Organizações Internacionais" na Wikipédia exibe a relação e descrição de 32 simulações abertas e de 20 internas registradas no Brasil, ainda que se estime que este número seja muito maior.
} 


\section{Quadro 01: Dez modelos de simulação da ONU mais relevantes no Brasil em} ordem de antiguidade.

\begin{tabular}{|c|c|c|c|c|c|c|c|c|}
\hline Nome do projeto & Instituição organizadora & Local & Público & Simulação & Duração & Implantação & $\begin{array}{l}\text { № Participantes } \\
\text { (Média) }\end{array}$ & $\begin{array}{l}N^{0} \text { Comitês } \\
\text { (Média) }\end{array}$ \\
\hline $\begin{array}{l}\text { Americas Model United Nations } \\
\text { (AMUN) }\end{array}$ & Universidade de Brasilia & Brasilia (DF) & \begin{tabular}{|l|} 
Ensinos \\
Fundamental, \\
Médio e Superior
\end{tabular} & $\begin{array}{l}\text { Organização da } \\
\text { Nações Unidas }\end{array}$ & 05 dias & 1998 & 250 & 9 \\
\hline MINIONU & $\begin{array}{l}\text { Pontifícia Universidade Católica } \\
\text { - Minas Gerais }\end{array}$ & Belo Horizonte (MG) & Ensino Médio & $\begin{array}{l}\text { Organização das } \\
\text { Nações Unidas }\end{array}$ & 4 dias & 2000 & 1000 & 20 \\
\hline $\begin{array}{l}\text { Modelos Simulações de } \\
\text { Organizações Internacionais } \\
\text { (SOI) }\end{array}$ & $\begin{array}{l}\text { Universidade Federal do Rio } \\
\text { Grande do Norte }\end{array}$ & Natal (RN) & $\begin{array}{l}\text { Ensino Médio e } \\
\text { Superior }\end{array}$ & $\begin{array}{l}\text { Tribunais } \\
\text { Internacionais }\end{array}$ & 5 dias & 2001 & 400 & 9 \\
\hline $\begin{array}{l}\text { Model United Nations (MUN- } \\
\text { UFRGS) }\end{array}$ & $\begin{array}{l}\text { Universidade Federal do Rio } \\
\text { Grande do Sul - Porto Alegre }\end{array}$ & Porto Alegre (RS) & Ensino Superior & $\begin{array}{l}\text { Organização da } \\
\text { Nações Unidas }\end{array}$ & 5 dias & 2003 & 200 & 7 \\
\hline ONUJr & $\begin{array}{l}\text { Universidade Federal } \\
\text { Fluminense }\end{array}$ & Niterói (RJ) & Ensino Médio & $\begin{array}{l}\text { Organização da } \\
\text { Nações Unidas }\end{array}$ & 5 dias & 2003 & 350 & 9 \\
\hline $\begin{array}{l}\text { Simulação da Organização das } \\
\text { Nações Unidas (SONU) }\end{array}$ & $\begin{array}{l}\text { Universidade Federal do Ceará } \\
\text { e Universidade Federal de } \\
\text { Fortaleza }\end{array}$ & Fortaleza (CE) & Ensino Superior & $\begin{array}{l}\text { Organização da } \\
\text { Naçōes Unidas }\end{array}$ & 4 dias & 2004 & 350 & 8 \\
\hline $\begin{array}{l}\text { Modelo Intercolegial de Relações } \\
\text { Internacionais (MIRIN) }\end{array}$ & $\begin{array}{l}\text { Potificia Universidade Católica- } \\
\text { Rio de Janeiro }\end{array}$ & Rio de Janeiro (RJ) & $\begin{array}{l}\text { Ensino Médio e } \\
\text { Superior }\end{array}$ & $\begin{array}{l}\text { Organismos } \\
\text { Internacionais }\end{array}$ & 5 dias & 2004 & 400 & 8 \\
\hline $\begin{array}{l}\text { United Nations Model of São } \\
\text { Paulo (UNSP) }\end{array}$ & $\begin{array}{l}\text { Universidade do Estado de São } \\
\text { Paulo - Franca (SP) }\end{array}$ & Franca (SP) & Ensino Superior & $\begin{array}{l}\text { Organização da } \\
\text { Nações Unidas }\end{array}$ & 4 dias & 2005 & 150 & 4 \\
\hline PoliONU & Colégio Poliedro-São Paulo & São Paulo (SP) & Ensino Médio & $\begin{array}{l}\text { Organização das } \\
\text { Nações Unidas }\end{array}$ & 4 dias & 2005 & 600 & 12 \\
\hline $\begin{array}{l}\text { São Paulo Model United Nations } \\
\text { (SPMUN) }\end{array}$ & Universidade de São Paulo & São Paulo (SP) & $\begin{array}{l}\text { Ensino Médio e } \\
\text { Superior }\end{array}$ & $\begin{array}{l}\text { Organização das } \\
\text { Nações Unidas }\end{array}$ & 5 dias & 2009 & 200 & 8 \\
\hline
\end{tabular}

Fonte: elaboração dos autores

A construção do material didático para apoio à simulação é feita por educadores e estudantes. Os guias de estudo são orientados para abarcar a perspectiva de interação com os saberes escolares, o que acarreta na reflexão ativa sobre os lugares do docente e do discente no processo educacional. Assim, cabe ao docente abandonar o papel de transmissor de conteúdos para se transformar num pesquisador-colaborador. O estudante, por sua vez, vê-se obrigado a transgredir a passividade e interagir no processo, construindo sentidos para o conhecimento. Em suma, acredita-se que a proposta por modelos de simulação da ONU incorpora as seguintes máximas:

- A relação de ensino e aprendizagem encaminha-se para a significação. Novos significados reconfiguram a rede de crenças do indivíduo, enriquecendo a sua visão de mundo. 
- Os estágios do conhecimento são um critério de referência, isto é, o movimento de construção dos conhecimentos é, via de regra, resultante da inserção do educando na sociedade e nas relações culturais que vive.

- As "bagagens" teóricas e de vida dos estudantes devem ser integradas no processo educacional. Uma vez que os estudantes não aprendem da mesma maneira, o sentido de diversidade da educação deve ser buscado em oposição aos modelos que criam generalizações para a aprendizagem.

Saliente-se, contudo, que o conhecimento só se torna significativo se não for concebido de forma linear. Como ratifica Hernández (1998), a estratégia de se trabalhar em projetos é uma das formas para promover o processo de aprendizagem não linear, pois o significante para o processo de ensino é a possibilidade de estabelecer critérios tangíveis de acompanhamento de objetivos de aprendizagem. Além de Hernández, com a organização metodológica nos projetos de trabalho, destaca-se, também, o conjunto de metodologias ativas nas quais, além do protagonismo dos estudantes nas escolhas e percursos de ensino, tem vulto o uso de novas tecnologias e estratégias de trabalhos individuais e em grupo, de forma a desenvolver habilidades múltiplas na educação (MORÁN, 2015).

\section{Metodologia}

Tendo em vista que o trabalho consiste em averiguar os impactos positivos e negativos da simulação da ONU pelo projeto IFMUNDO, a descrição dos aspectos metodológicos se restringirá às estratégias para o levantamento e a análise das percepções dos estudantes. Entretanto, para que melhor se compreendam as circunstâncias em que os questionários foram aplicados, apresenta-se abaixo, de maneira sequencial, as etapas de construção e realização da simulação:

1. Participação de dez estudantes do IFNMG Campus Almenara na MiniONU, em Belo Horizonte (MG), em outubro de 2016. A experiência adquirida por esses estudantes os habilitou a atuarem no IFMUNDO como diretores de comitês. 
2. Elaboração do projeto IFMUNDO - ensino, pesquisa e extensão, e protocolo na instituição de ensino em março de 2017.

3. Divisão das turmas do ensino médio em delegações de 10 a 15 estudantes, e, em embaixadas, com atribuição de países por meio de sorteio, em abril de 2017.

4. Aplicação da primeira rodada de questionários, em abril de 2017.

5. Realização de seminários e simulações curtas em sala de aula para familiarizar os estudantes com as regras da simulação, entre abril e maio de 2017.

6. Realização do evento com realização de rodadas dos comitês e exposição das embaixadas, em junho de 2017.

\section{Aplicação da segunda rodada questionários, em junho de 2017.}

8. Organização, tabulação, processamento dos resultados do questionário, análise e discussão dos resultados, entre agosto e dezembro de 2017.

Esclareça-se que a escolha pela divisão das delegações em comitês e embaixadas foi uma estratégia utilizada para garantir a participação total dos estudantes do ensino médio em ações voltadas ao estímulo e ao desenvolvimento de pesquisas sobre aspectos sociais, econômicos, políticos e culturais dos países envolvidos nos comitês. Nos comitês os estudantes participaram da simulação efetiva, enquanto as embaixadas funcionaram como uma feira de cultura em que cada delegação é representada em um estande (Fotos 01 e 02). 


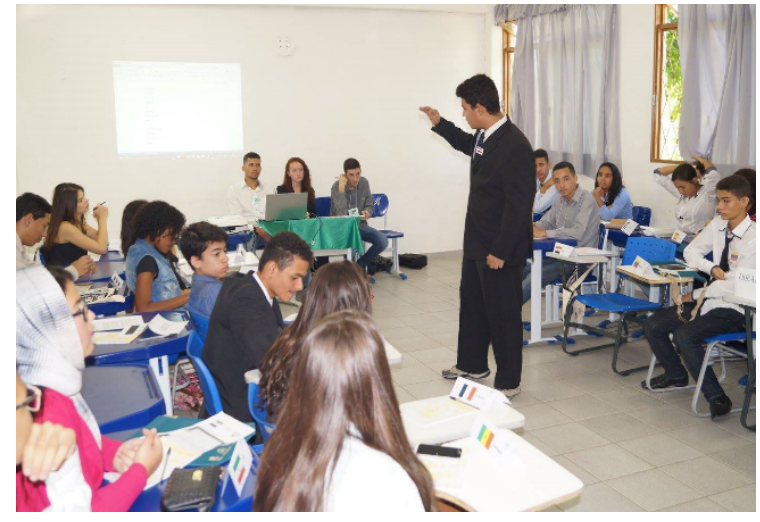

Foto 1: Simulação do comitê da Organização Mundial do Turismo (OMT).

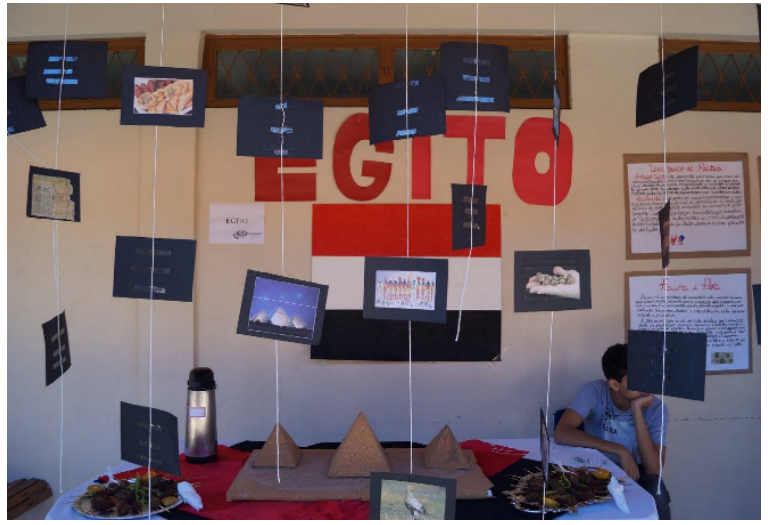

Foto 2: Estande da delegação do Egito.

Conforme Gil (2010), a pesquisa descritiva tem como finalidade descrever as diversas características apresentadas em uma realidade, enquanto a pesquisa explicativa procura evidenciar os fatores que contribuem para a ocorrência de determinado fenômeno. De modo geral, a abordagem qualitativa procura descrever significados que são socialmente construídos e que assumem uma dimensão subjetiva. Enfatiza-se, portanto, os processos, os discursos e conteúdos nas interações sociais. Já a abordagem quantitativa busca descrever os significados da realidade estudada de forma objetiva, permitindo uma análise focalizada, pontual e estruturada dos dados. Triola (1999) e Rogerson (2012) demonstram, neste contexto, que os modelos estatísticos são componentes essenciais do método científico, pois permitem a realização de generalizações a partir de um grande conjunto de evidências, que por sua vez servem de suporte à elaboração de modelos teóricos.

Optou-se por mensurar a percepção dos estudantes sobre a qualidade do evento por meio da aplicação de um survey, de caráter quantitativo, interseccional, com amostragem não-probabilística e baseada na confiança nos sujeitos disponíveis. Segundo Babbie (1999), o survey representa um tipo especial de pesquisa social empírica que objetiva descrever uma população por meio de seus atributos, além de, quando possível, propor explicações para o que se observou.

Gil (2008) ressalta que, em sua maioria, os surveys não se dedicam a toda a população estudada, mas a uma amostra significativa dela. Visam o conhecimento 
direto da realidade, a economia de recursos, a celeridade e a quantificação das informações sobre o universo analisado. Como limitadores, o autor enumera a subjetividade da percepção das pessoas, a baixa capacidade de aprofundamento sobre os fenômenos sociais e uma visão estática da realidade que restringe a percepção de mudanças. Assim, seriam mais adequados para estudos descritivos do que para explicativos.

No mesmo sentido, Vaus (2002) esclarece que os surveys não se restringem ao uso de questionários, mas podem recorrer a outras estratégias de coleta de dados, como pesquisas estruturadas e em profundidade, além de observações, desde que a coleta seja estruturada, sistemática e composta por um conjunto de variáveis passíveis de serem organizadas por tabulação, o que viabiliza a comparação entre casos levantados, a proposição de sínteses e a explicação de fenômenos porventura observados. Em termos éticos, um survey deve considerar os seguintes princípios: participação voluntária, consentimento informado, respeito à confidencialidade, ao anonimato e à privacidade, além de não causar qualquer tipo de dano aos entrevistados.

A escolha pelo survey se justificou pela dificuldade de entrevistar todos os estudantes no curto espaço de tempo de realização das campanhas, circunstância que impossibilitou tanto a realização de censo, quanto de pesquisa amostral probabilística. Do total de 294 estudantes matriculados no ensino médio integrado, a pesquisa foi capaz de alcançar em cada uma das campanhas uma média de $70 \%$ deles (208 e 209, respectivamente), excetuando-se as recusas. Para efeitos comparativos, utilizou-se nos resultados apenas os questionários que foram respondidos pelos mesmos estudantes nas duas campanhas, totalizando 190, o que corresponde a $64,6 \%$ do total.

Para a avaliação da simulação como instrumento didático, elaborou-se um questionário que envolveu cinco temas de abordagem (Quadro 02). Esse questionário foi aplicado antes e depois da simulação. Nos temas um a três buscouse avaliar em que medida os estudantes conheciam a ONU, os temas ali discutidos, e o papel desta instituição na mediação de conflitos mundiais. Nos temas quatro e cinco, procurou-se captar a percepção dos estudantes sobre o seu nível de 
engajamento em relação ao evento e ao envolvimento da comunidade escolar. No questionário, cada estudante indicou a sua percepção sobre os temas propostos em uma escala de concordância do tipo Likert, geralmente utilizada para expressar um posicionamento, atitude ou opinião relacionada a um único item (VAUS, 2002). A escala variou de zero a dez nas vinte questões propostas, sendo zero equivalente a "nenhum conhecimento", cinco a "médio conhecimento", e 10 a "total conhecimento" sobre o item arrolado. Realizou-se o pré-teste bem-sucedido em um pequeno grupo de estudantes com o objetivo de experimentar o entendimento dos enunciados e comandos do questionário.

Embora algumas questões apresentem escopo genérico que poderia induzir os entrevistados a erros de autopercepção, as médias das respostas obtidas revelaram-se muito inferiores às esperadas pelos autores, o que permite conjecturar que os entrevistados buscaram expor suas percepções de maneira fidedigna. Contudo, estudos posteriores poderão conter questões de maior concretude e objetividade, que permitam a proposição de inferências cognitivas, e que abordem, além de temas específicos de interesse universal, características particulares sobre o funcionamento da ONU.

Os dados obtidos foram tabulados, sistematizados e processados em ambiente Microsoft Excel 2013. A análise dos resultados levou em conta a comparação das médias das percepções em cada questão e em cada grupo de questões. Além disso, os dados dos entrevistados que participaram dos comitês foram separados daqueles que participaram das embaixadas. Tal separação demonstrou diferenças significativas tanto entre os perfis de estudantes que escolheram uma ou outra modalidade, quanto dos ganhos referentes a cada uma das modalidades da simulação.

\section{Quadro 2: Estrutura do questionário aplicado nas campanhas 01 e 02.}


ALEX LARA MARTINS \& ALFREDO COSTA \& LEONARDO M. P.

\begin{tabular}{|c|c|}
\hline Tema $^{\star}$ & Questão \\
\hline \multirow{4}{*}{$\begin{array}{l}\text { Tema } 01 \text { - Questôes } \\
\text { Gerais sobre a ONU }\end{array}$} & $\begin{array}{l}\text { 1) O quanto você sabe sobre os princípios gerais da Organização das Nações } \\
\text { Unidas (ONU)? }\end{array}$ \\
\hline & 2) $\mathrm{O}$ quanto você sabe sobre os objetivos da agenda 2030 da ONU? \\
\hline & $\begin{array}{l}\text { 3) O quanto você acha que as propostas e as ações da ONU são capazes de } \\
\text { modificar o mundo? }\end{array}$ \\
\hline & $\begin{array}{l}\text { 4) Na sua opinião, qual é a relevância da ONU na promoção dos Direitos } \\
\text { Humanos no mundo? }\end{array}$ \\
\hline \multirow{5}{*}{$\begin{array}{c}\text { Tema } 02 \text { - } \\
\text { Conhecimentos } \\
\text { especificos sobre os } \\
\text { comitês }\end{array}$} & $\begin{array}{l}\text { 5) Qual é o seu nivel de conhecimento sobre o tema: produção de alimentos do } \\
\text { mundo? }\end{array}$ \\
\hline & $\begin{array}{l}\text { 6) Qual é o seu nivel de conhecimento sobre o tema ciência e inovação no } \\
\text { mundo? }\end{array}$ \\
\hline & 7) Qual é o seu nivel de conhecimento sobre a gestão das águas no mundo? \\
\hline & 8) Qual é o seu nível de conhecimento sobre o turismo sustentável no mundo? \\
\hline & $\begin{array}{l}\text { 9) Qual é o seu nivel de conhecimento sobre as questões relacionadas à } \\
\text { inserção da mulher no mercado de trabalho? }\end{array}$ \\
\hline \multirow{3}{*}{$\begin{array}{c}\text { Tema } 03 \text { - Percepção } \\
\text { sobre conflitos } \\
\text { internacionais e pape } \\
\text { da ONU }\end{array}$} & $\begin{array}{l}\text { 10) Qual é o seu nivel de conhecimento sobre os conflitos mundiais atuais e as } \\
\text { guerras entre paises? }\end{array}$ \\
\hline & $\begin{array}{l}\text { 11) Qual é o nível de confiança nos relatos de conflitos reportados pela imprensa } \\
\text { internacional? }\end{array}$ \\
\hline & $\begin{array}{l}\text { 12) O quanto você acha que as decisões tomadas por organismos internacionais } \\
\text { afetam o seu dia-a-dia? }\end{array}$ \\
\hline \multirow{4}{*}{$\begin{array}{c}\text { Tema } 04 \text { - } \\
\text { Engajamento do } \\
\text { estudante em relação } \\
\text { ao evento }\end{array}$} & $\begin{array}{l}\text { 13) O quanto você está familiarizado com o país que você representa no } \\
\text { IFMUNDO? }\end{array}$ \\
\hline & 14) O quanto você conhece sobre os demais paises participantes do IFMUNDO? \\
\hline & $\begin{array}{l}\text { 15) O quanto você conhece sobre as funções dos Conselhos e Comitês da } \\
\text { ONU? }\end{array}$ \\
\hline & $\begin{array}{l}\text { 16) O quanto você sabe sobre as funções dos delegados e embaixadores na } \\
\text { ONU? }\end{array}$ \\
\hline \multirow{4}{*}{$\begin{array}{c}\text { Tema } 05 \text { - Percepção } \\
\text { sobre o envolvimento } \\
\text { da comunidade } \\
\text { escolar }\end{array}$} & $\begin{array}{l}\text { 17) na sua opinião, em que nível o IFNMG-Almenara promove ações que levam } \\
\text { os estudantes a refletir politicamente e modificar a sua realidade? }\end{array}$ \\
\hline & $\begin{array}{l}\text { 18) Na sua opinião, qual é o nivel de ervolvimento do IFNMG-Almenara em } \\
\text { relação aos problemas globais? }\end{array}$ \\
\hline & $\begin{array}{l}\text { 19) Na sua opinião, qual é o nivel de envolvmento dos professores do IFNMG- } \\
\text { Almenara em relação aos problemas globais? }\end{array}$ \\
\hline & $\begin{array}{l}\text { 20) Na sua opinião, qual é o nivel de envolvimento dos alunos IFNMG-Almenara } \\
\text { em relação aos problemas globais? }\end{array}$ \\
\hline
\end{tabular}

Fonte: elaborado pelos autores. *As cores selecionadas para cada tema visam facilitar a leitura dos gráficos apresentados nos resultados.

\section{Análise e discussão dos resultados}

A Tabela 01 mostra o desempenho médio das respostas nas campanhas inicial e final por comitês e embaixadas. Já as Figuras 01 e 02, baseadas nos dados da Tabela 01, apresentam dois gráficos referentes ao desempenho dos entrevistados participantes, respectivamente, de comitês e embaixadas. O primeiro 
gráfico mostra as respostas médias para cada questão nas campanhas inicial e final, e ressalta, por meio de cores, a diferença entre o desempenho inicial e final. $O$ segundo gráfico, complementar, apresenta o resultado do somatório das diferenças entre as médias apresentadas pelos temas, em que cada cor representa a contribuição de um tema. Sua função principal é revelar em quais aspectos a simulação foi mais ou menos eficiente em sua função pedagógica. A Figura 03, por sua vez, revela a diferença percentual entre as respostas médias iniciais e finais por comitê e embaixada.

Cerca de metade do ganho potencial da percepção dos participantes 53,8\% nos comitês (Fig. 01) e 47,7\% nas embaixadas (Fig. 02) - deriva do tema 04, que está relacionado ao engajamento dos estudantes no evento e ao seu conhecimento sobre as funções dos conselhos da ONU. Isso pode significar, de um lado, que as práticas parlamentares fincadas no decoro e mobilizadas para a resolução conjunta de problemas globais foram bem assimiladas pelos estudantes (questões 15 e 16). Por outro lado, o exercício de se colocar no lugar de um "outro", cujos valores contradizem a visão de mundo comum, foi bem compreendido pelos participantes (questões 13 e 14). A efetiva compreensão de aspectos formais das regras da simulação equilibrou os baixos ganhos perceptuais relacionados aos conhecimentos específicos exigidos pelas temáticas discutidas em cada comitê. Ainda mais quando se analisa estes resultados conjuntamente com os ganhos perceptuais do tema 01 - "questões gerais sobre a ONU" - com 26,5\% e 21,9\%. Este resultado chama atenção porque representa o êxito da metodologia em sensibilizar os estudantes sobre o funcionamento da ONU e seus temas atuais.

O tema 05, "percepção sobre o envolvimento da comunidade escolar", apresentou algumas tendências que merecem um olhar precavido. Os resultados deste estrato foram de apenas 3,1\% nos comitês, e - $0,1 \%$ nas embaixadas. Isso pode significar tanto que os docentes e a escola não promovem ações efetivas relacionadas a temas de relevância global, quanto pode significar que o IFMUNDO foi apenas uma das diversas ações promovidas pelos docentes e pela escola. Para se estabelecer a hipótese mais consistente, neste caso é necessário cruzar os dados com os resultados de outros estratos temáticos. Os temas 02 e 03 - 
"conhecimentos específicos sobre os comitês" e "percepção sobre conflitos internacionais" - tiveram ganho perceptual abaixo da média, especialmente dentro da modalidade comitê. Ora, tendo em vista que a própria Lei de Diretrizes e Bases da Educação (Lei no 9.394 de 20 de dezembro de 1996) se inspira nos ideais da solidariedade humana, da pluralidade de ideias e da consideração do ensino para a diversidade, não se pode rejeitar a hipótese de que as habilidades dos temas 02 e 03 são adquiridas, no mais das vezes, em sala de aula, por meio de relações tradicionais de ensino e aprendizagem, especialmente nas aulas de história e geografia. A percepção variou pouco porque a média inicial das notas era mais alta do a média de notas dos temas 01 e 05, em que houve grande variação. Ressalte-se que a metodologia de projetos, baseada na criação de situações-problema, não prescinde totalmente de práticas pedagógicas tradicionais. Olhando por este prisma, os baixos resultados dos temas 02 e 05 podem ter alguma relação com o modo pelo qual os professores e a escola estabelecem cotidianamente os conteúdos de relevância global em sala de aula. Pode-se conjecturar que o aumento da média tenha a ver com a vivência de outra metodologia pedagógica, em que os alunos têm contato com os conteúdos de maneira mais imersiva do que no modelo de sala de aula, o que pode ter acarretado em aumento da percepção sobre a complexidade das temáticas.

A questão 04 merece atenção especial deste trabalho, já que incide na percepção dos estudantes sobre o papel da ONU na promoção dos Direitos Humanos. Considerando os dados das figuras 04 e 05, embora as linhas de tendência indiquem mais ganhos significativos na modalidade da embaixada do que na outra modalidade (8,9\% contra 4,3\%), a percepção inicial do comitê parte do patamar mais alto registrado em qualquer resposta da campanha inicial (Tab. 01). Além disso, este patamar inicial está bem acima das respostas às questões específicas trabalhadas dentro de cada comitê. Esses dados corroboram o que se disse acerca da abrangência dos eixos formativos relacionados aos Direitos Humanos, que servem como um grande guarda-chuva abaixo do qual as temáticas específicas são consideradas. Neste caso, o significado do que sejam Direitos Humanos corresponde à bagagem teórica mobilizada pelos estudantes diante das situações-problema, o que fortalece o caráter holístico de sua formação. 
Tabela 1: Desempenho médio das respostas nas campanhas inicial e final por comitês e embaixadas.

\begin{tabular}{|c|c|c|c|c|c|}
\hline \multirow{3}{*}{ Temas } & \multirow{3}{*}{ Questões } & \multicolumn{4}{|c|}{ Desempenho } \\
\hline & & \multicolumn{2}{|c|}{ Comitê } & \multicolumn{2}{|c|}{ Embaixada } \\
\hline & & Incial & Final & Incial & Final \\
\hline \multirow{4}{*}{$\begin{array}{c}\text { Tema } 01 \text { - Questöes Gerais } \\
\text { sobre a ONU }\end{array}$} & Questão 01 & 3,8 & 5,9 & 3,3 & 5,3 \\
\hline & Questão 02 & 1,1 & 3,1 & 0,9 & 1,9 \\
\hline & Questão 03 & 6,5 & 7,2 & 5,9 & 6,6 \\
\hline & Questão 04 & 7,0 & 7,3 & 5,8 & 6,3 \\
\hline \multirow{5}{*}{$\begin{array}{c}\text { Tema } 02 \text { - Conhecimentos } \\
\text { específicos sobre os } \\
\text { comitês }\end{array}$} & Questão 05 & 4,5 & 4,8 & 3,9 & 4,6 \\
\hline & Questão 06 & 4,5 & 5,2 & 4,0 & 4,9 \\
\hline & Questão 07 & 4,5 & 5,0 & 3,8 & 4,4 \\
\hline & Questão 08 & 3,7 & 4,3 & 3,5 & 4,4 \\
\hline & Questão 09 & 6,1 & 6,1 & 4,9 & 5,5 \\
\hline \multirow{3}{*}{$\begin{array}{c}\text { Tema } 03 \text { - Percepção sobre } \\
\text { conflitos internacionais e } \\
\text { papel da ONU }\end{array}$} & Questão 10 & 6,2 & 6,2 & 5,0 & 5,6 \\
\hline & Questão 11 & 4,0 & 4,5 & 3,3 & 4,1 \\
\hline & Questão 12 & 6,0 & 6,5 & 5,1 & 5,9 \\
\hline \multirow{4}{*}{$\begin{array}{c}\text { Tema } 04 \text { - Engajamento do } \\
\text { estudante em relação ao } \\
\text { evento }\end{array}$} & Questão 13 & 3,0 & 5,9 & 2,7 & 5,7 \\
\hline & Questão 14 & 3,6 & 4,6 & 3,4 & 4,8 \\
\hline & Questão 15 & 3,0 & 5,6 & 2,4 & 4,5 \\
\hline & Questão 16 & 2,7 & 6,5 & 2,8 & 5,6 \\
\hline \multirow{4}{*}{$\begin{array}{c}\text { Tema } 05 \text { - Percepção sobre } \\
\text { o envolvimento da } \\
\text { comunidade escolar }\end{array}$} & Questão 17 & 6,7 & 6,7 & 6,2 & 6,2 \\
\hline & Questão 18 & 5,6 & 5,7 & 5,5 & 5,2 \\
\hline & Questão 19 & 6,0 & 5,9 & 5,5 & 5,3 \\
\hline & Questão 20 & 4,3 & 4,9 & 4,3 & 4,8 \\
\hline \multicolumn{2}{|l|}{ Média } & 4,6 & 5,6 & 4,1 & 5,1 \\
\hline \multicolumn{2}{|l|}{ Ganho } & \multicolumn{2}{|c|}{$20,9 \%$} & \multicolumn{2}{|c|}{$23,9 \%$} \\
\hline
\end{tabular}

Fonte: Elaborado pelos autores.

Figura 1: Percepção dos estudantes participantes de comitês nas duas campanhas. 
ALEX LARA MARTINS \& ALFREDO COSTA \& LEONARDO M. P.

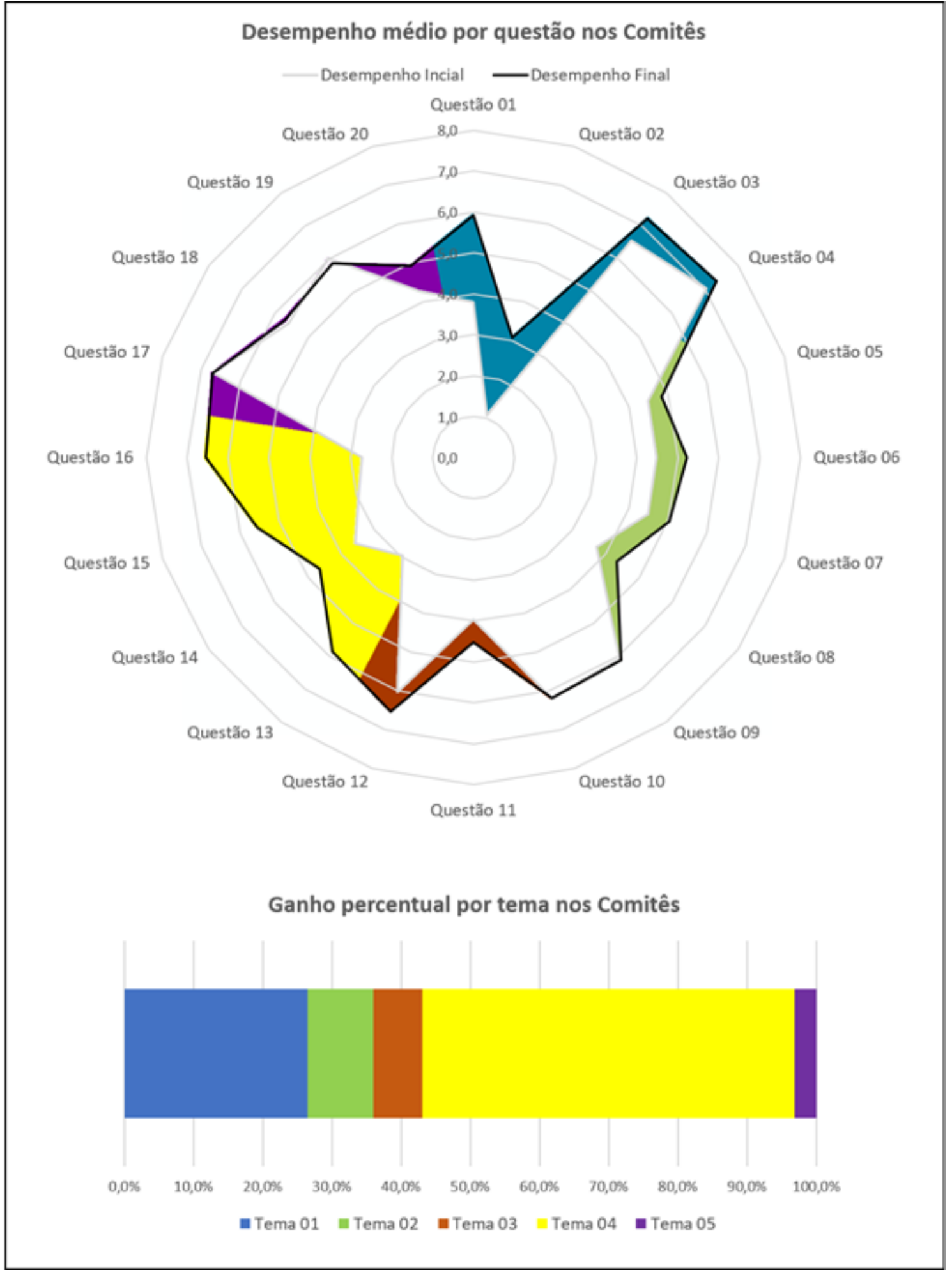

Fonte: Elaborado pelos autores.

Figura 2: Percepção dos estudantes participantes de Embaixadas nas duas campanhas. 


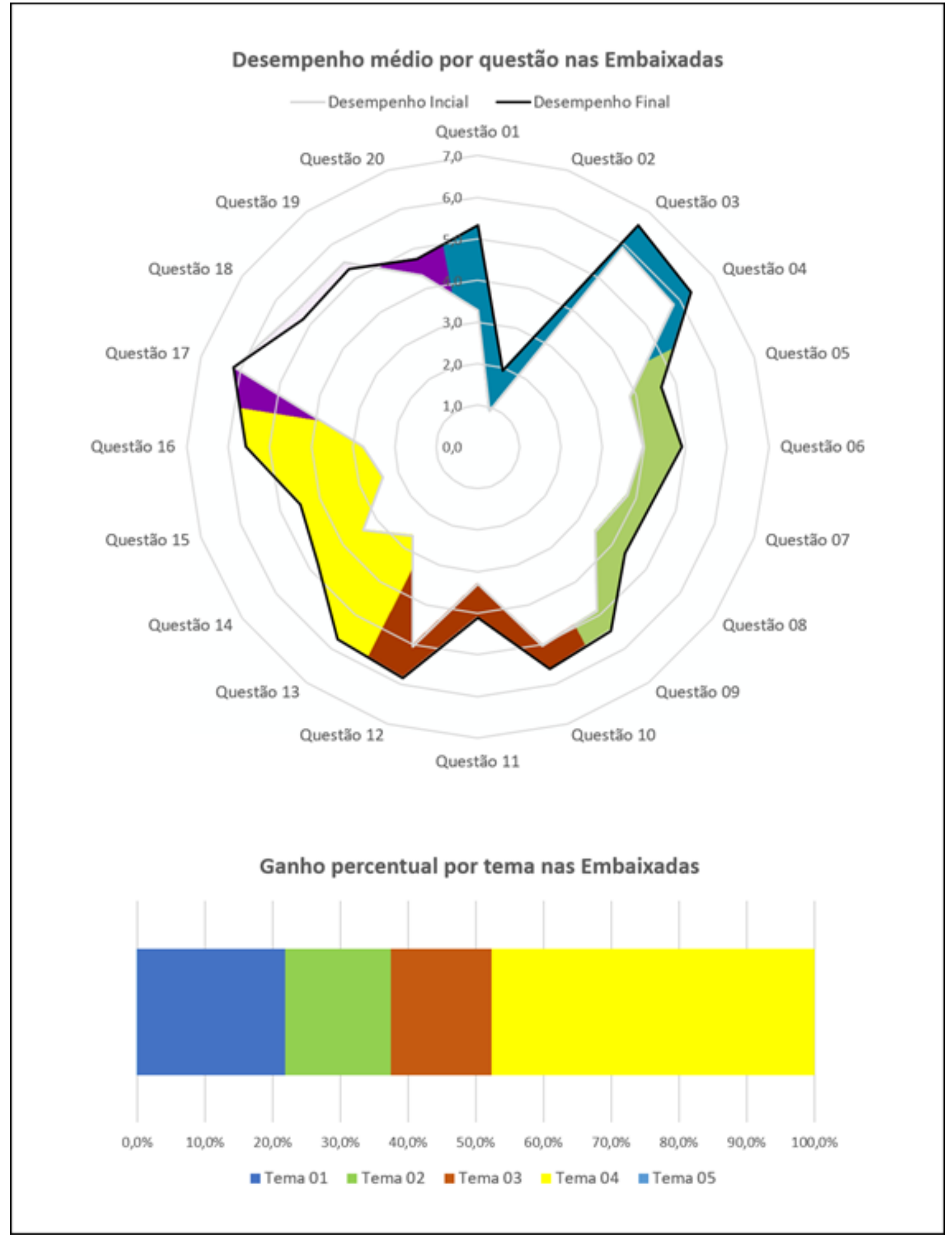

Fonte: elaborado pelos autores.

Figura 3: Ganhos percentuais entre as percepções iniciais e finais, por questão, nos comitês e embaixadas. 
ALEX LARA MARTINS \& ALFREDO COSTA \& LEONARDO M. P.

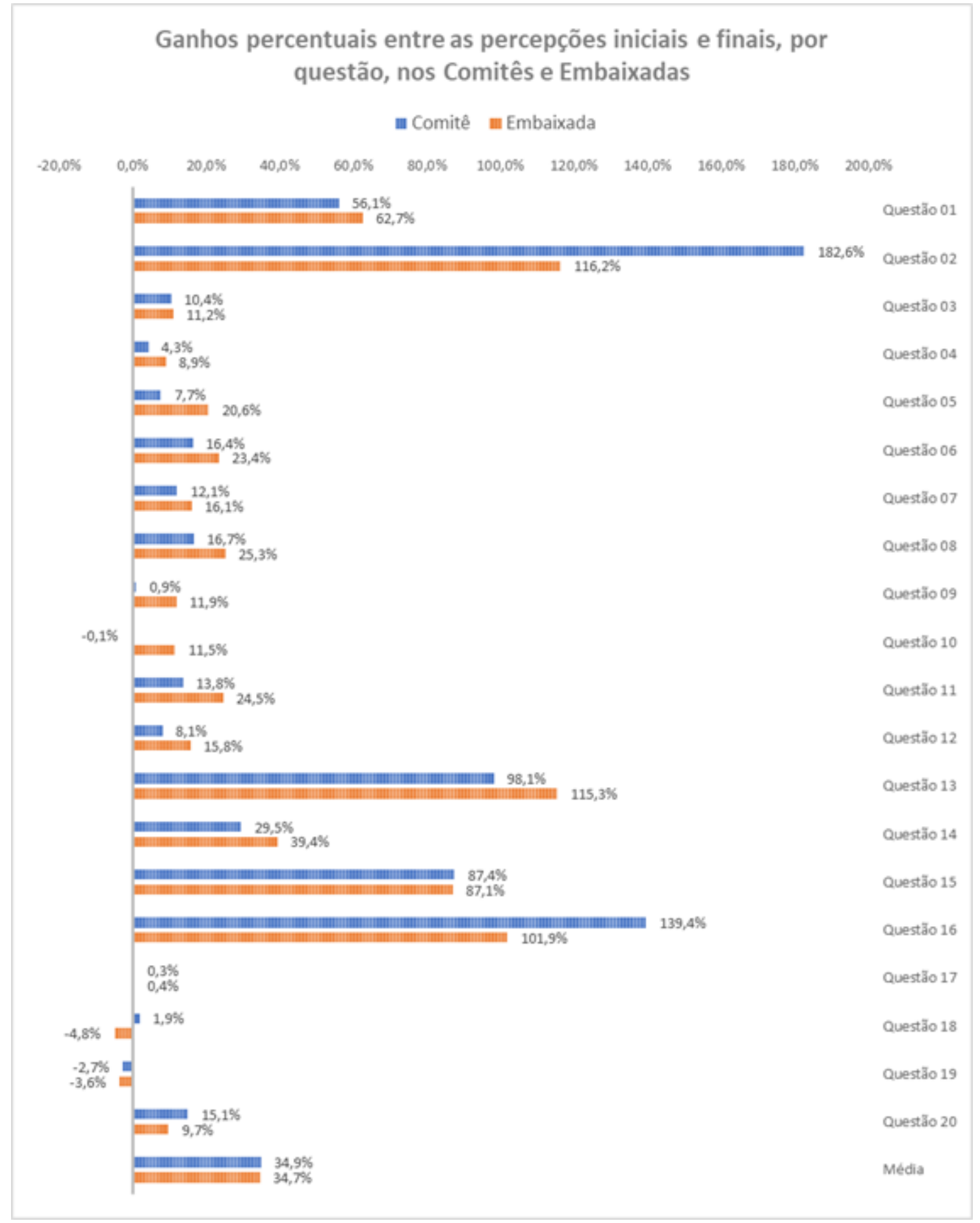

Fonte: elaboração dos autores

Figura 4: Desempenho dos comitês em relação à questão 04 - "Na sua opinião, qual é a relevância da ONU na promoção dos Direitos Humanos no mundo?", por frequência de respostas nas duas campanhas. 
ALEX LARA MARTINS \& ALFREDO COSTA \& LEONARDO M. P.

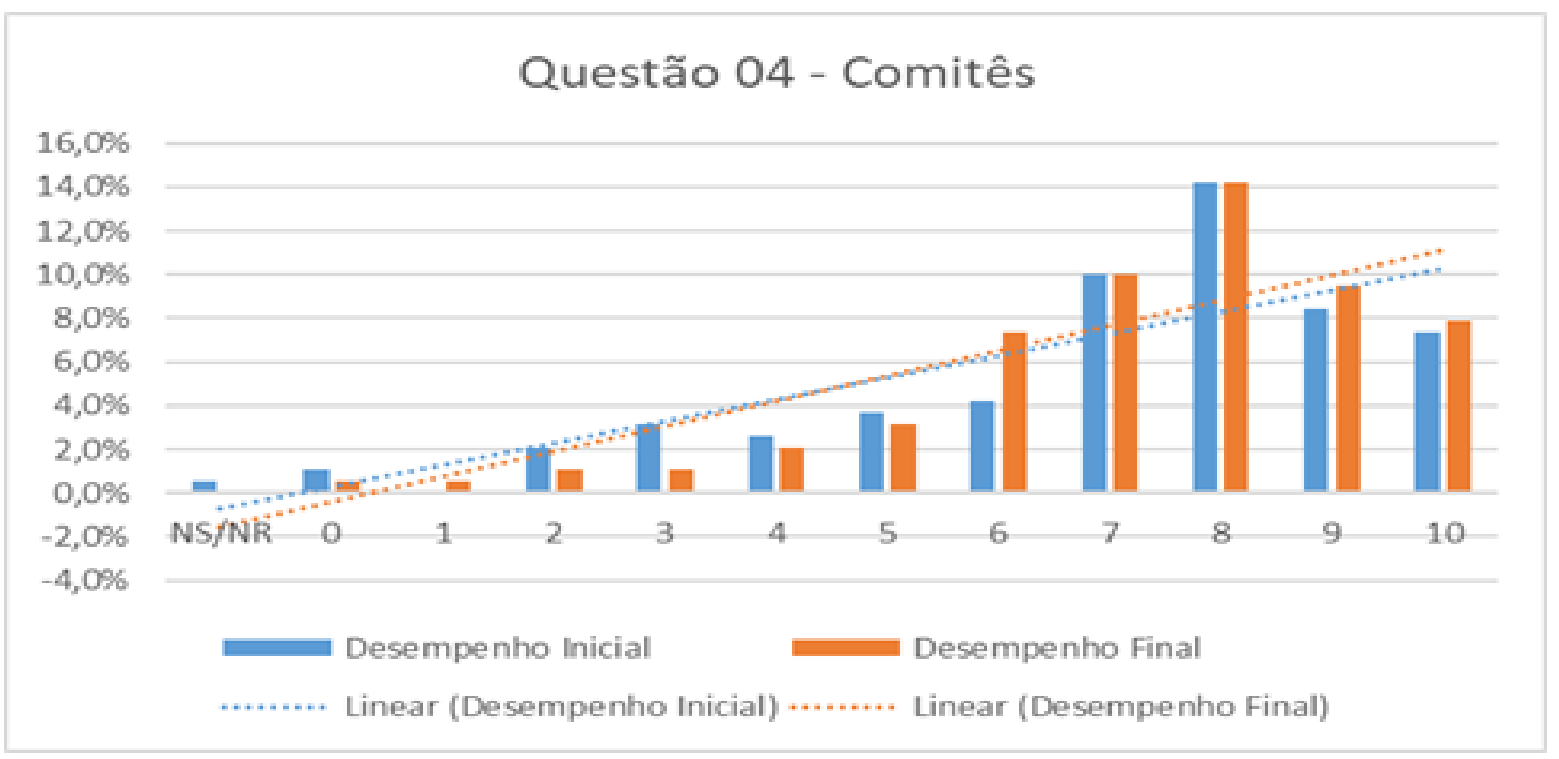

Fonte: elaboração dos autores

Figura 5: Desempenho das embaixadas em relação à questão 04 - "Na sua opinião, qual é a relevância da ONU na promoção dos Direitos Humanos no mundo?", por frequência de respostas nas duas campanhas.

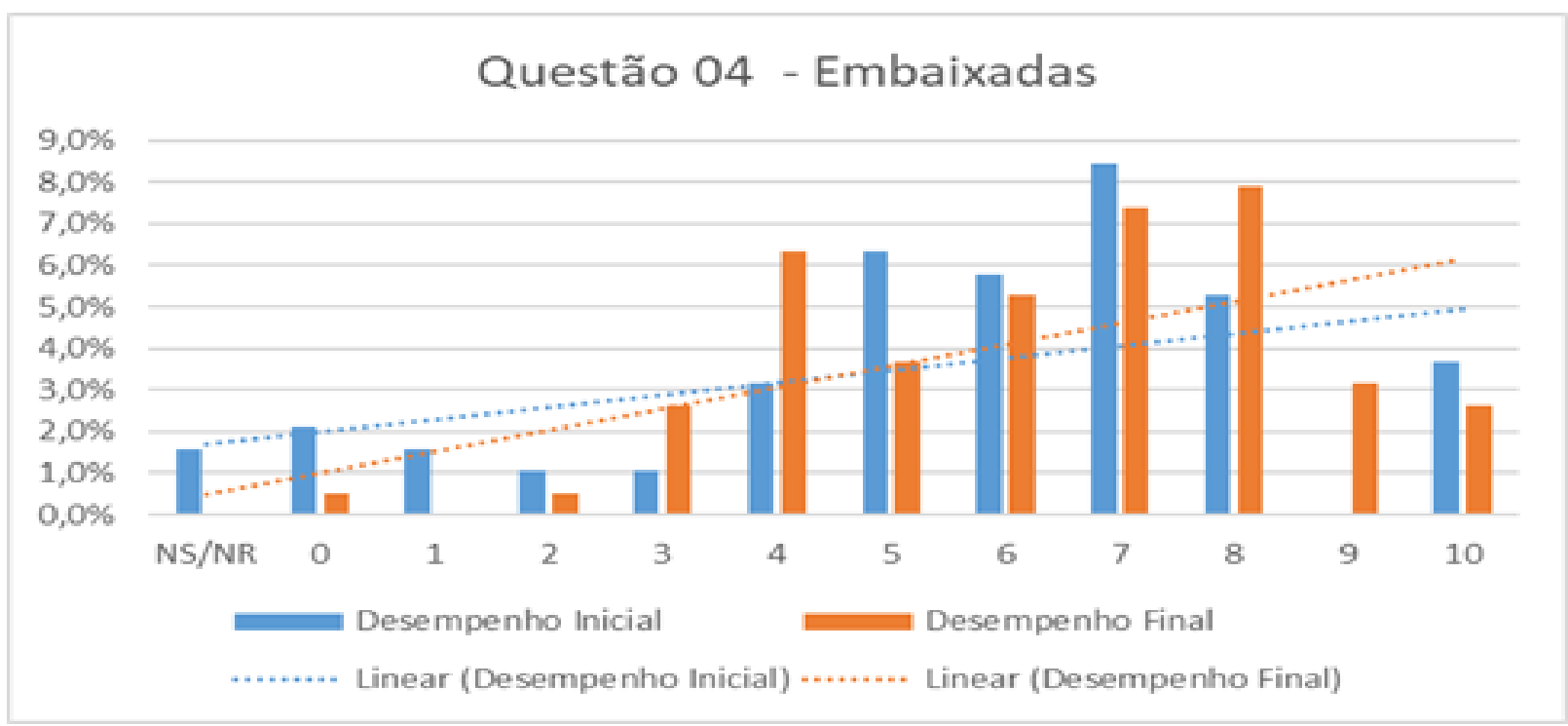

Fonte: elaboração dos autores

\section{Considerações Finais}

Paulo Freire demonstra, desde a década de 1960, que os processos de ensino incidem sobre a inclusão de todos os sujeitos no contexto educacional. Sabendo-se que os processos educacionais ocorrem em diferentes contextos 
sociais, e que a sociedade contemporânea é marcada pela intensa integração econômica, política e cultural, deve-se pensar em novas configurações escolares que sejam dinâmicas e comprometidas com a resolução de problemas globais. Nesse sentido, a organização de modelos de simulação revela-se como uma importante ferramenta pedagógica de construção de saberes entre educadores e educandos em que os processos de estudos respeitam as particularidades dos educandos em suas etapas de integração nas simulações.

Durante as simulações, o "eu" assume o papel de um "outro" distante, com valores e visão de mundo diferentes. A reflexão sobre o modo de vida e os valores de outros povos encadeia um processo de questionamento sobre alguns aspectos morais da própria sociedade em que se vive. Por outro lado, colocar-se no lugar deste "outro" fortalece a noção de uma identidade plural, respeitosa e compreensiva. Nesse cenário complexo, a compreensão do "outro" é a chave para a entrada dos estudantes no cenário das simulações. Ao ser desafiado a apresentar as ideias e soluções de outros povos para os problemas mundiais, o educando se torna capaz de entender o mundo no plural e não no singular, o que lhe permite superar as contradições entre a identidade e a heterogeneidade e buscar um princípio comum de humanidade, tal como aponta a ECG e se efetiva com a pedagogia de simulação.

No caso da simulação IFMUNDO, os ganhos vão além dos aprimoramentos educacionais apresentados e do engajamento de toda a instituição de ensino ao colocar na ordem do dia os debates que pautam as principais questões mundiais. É possível que os ganhos mais significativos digam respeito àquilo que é subjetivo e intangível, isto é, a própria formação humana dos estudantes, a descoberta de novas perspectivas e o reconhecimento da diferença como princípio básico da noção de Direitos Humanos. Essa é, provavelmente, a maior contribuição da simulação para a formação dos estudantes como cidadãos globais.

Percebeu-se, também, que esta estratégia possibilita reflexões importantes quanto aos rumos da Educação para o século XXI. Para além das grandes críticas ao modelo tradicional de ensino, marcado predominantemente pela relação pouco ativa do estudante sobre os processos de escolhas de estudo, o processo de organização do modelo de simulação, por mais que tenha surgido como proposição 
de docentes aos estudantes no IFNMG Campus Almenara, é, na prática, uma ação de exercício da autonomia, já que estudantes e professores interagem com relativa igualdade de ação. Cabe aos estudantes o protagonismo da construção e prática da simulação.

Os resultados apontados indicam a importância da horizontalização das relações entre docentes e discentes como estratégia para o desenvolvimento de competências cognitivas pessoais e sociais que - como ensina José Morán exigem, para além das formas tradicionais, atitudes proativas, colaborativas empreendedoras e focadas no indivíduo.

Os resultados também indicam possíveis imersões acerca das capacidades pedagógicas da metodologia da simulação. A análise em tela, conforme evidenciado, referiu-se à primeira edição do evento e, por isso, teve caráter generalista e exploratório. Espera-se que, nas próximas edições do evento, possam ser feitas imersões que incorporem especificidades acerca dos temas trabalhados, por exemplo, a percepção sobre objetivos específicos da Agenda 2030, questões relacionadas às liberdades individuais, questões contemporâneas de interesse mundial, entre outras, relacionadas ao compromisso com a cidadania global.

Esse projeto e seus desdobramentos educacionais permitem acreditar na importância da inovação educacional calcada no fortalecimento da crença e nas escolhas (certas e erradas) construídas pelo coletivo de pessoas envolvidos nos processos educacionais.

\section{Agradecimentos}

Agradecemos ao estudante do curso de Tecnólogo em Processos Gerenciais Eduardo Batista Braga Santos, bolsista do projeto de extensão “"IFMUNDO - Modelo de Simulação da ONU no IFNMG-Almenara” ao longo do segundo semestre de 2017, via Edital N 15/2017 de Extensão do IFNMG Campus Almenara, registrado na Pró-Reitoria de Extensão sob o número 114/2017. 
Estendemos os agradecimentos aos estudantes e professores que, através de árduo trabalho, viabilizaram a realização do evento IFMUNDO 2017.

\section{Referências Bibliográficas}

BABBIE, Earl. Métodos de pesquisa de Survey; tradução de Guilherme Cezarin Belo Horizonte: Ed. UFMG. 519p, 1999

BOHM, David. Sobre a Criatividade. Tradução de Rita de Cássia Gomes. São Paulo: Unesp, 2011.

DE PAULA, Ana Paula Lattaro; BERGAMASCHI FILHO, Edson; DOS SANTOS, Gisele Guerra. Análise da Eficiência de Ferramentas de Simulação Organizacional Enquanto Facilitadoras da Aplicação de Teorias para o curso de Graduação em Administração. Revista Libertas. v. 1, n. 1, 2011.

DOWBOR, Ladislau. Educação e desenvolvimento local. In: MAFRA, Jason [et al.] (org.). Globalização, educação e movimentos sociais: 40 anos da Pedagogia do Oprimido. São Paulo: Editora e Livraria Instituto Paulo Freire: Editora Esfera, 2009.

FREIRE, Ana Maria. Educação para a Sustentabilidade: implicações para o currículo escolar e para a formação de professores. Pesquisa em Educação Ambiental, vol. 2, n. 1, p. 141-154, 2007.

FREIRE, Paulo. Educação como prática de liberdade. Rio de Janeiro: Paz \& Terra, 1967.

GIL, Antonio Carlos. Métodos e técnicas de pesquisa social. 6. ed. - São Paulo: Atlas, 2008. 200 p.

HERNÁNDEZ, Fernando. Transgressão e mudança na educação: os projetos de trabalho. Tradução de Jussara H. Rodrigues. Porto Alegre: Artmed, 1998.

LANORD, C. \& DEYRA, M. The Jean Pictet Competition, In: International Review of the Red Cross, Vol.35, Issue 306, Jun. 1995, pp.341-346.

LEVY, Brett. Advising a Model United Nations club: A scaffoldedyouthadultpartnershiptofosteractiveparticipationandpoliticalengagement. Teaching and Teacher Education, vol. 59, no 1, p. 13-27, 2016.

MARUM, Carla Szazi. Influência da rede PEA-UNESCO na implantação de programas de educação para sustentabilidade em escolas parceiras. Revbea, vol. 11, n. 2, p. 54-73, 2016.

MCAVOY, Paula; HESS, Diana. Classroom deliberation in an era of political polarization. Curriculum Inquiry, vol. 43, n. 1, p. 14-47, 2013. 
MODELO DE ORGANIZAÇÕES INTERNACIONAIS. In: WIKIPÉDIA, a enciclopédia livre. Flórida: Wikimedia Foundation, 2018. Disponível em: <https://pt.wikipedia.org/w/index.php?title=Modelo_de_organiza\%C3\%A7\%C3\%B5e s_internacionais\&oldid=51235764> Acessado em 9 de fevereiro de 2018.

MORÁN, José. Mudando a educação com metodologias ativas. IN: SOUZA, Carlos Alberto; MORALES, Ofélia (orgs.). Convergências Midiáticas, Educação e Cidadania: aproximações jovens. Vol. II. Ponta Grossa: Foca Foto-PROEX/UEPG, 2015. Disponível em: <https://goo.gl/XbMRvb> Acessado em 8 de abril 2018.

MORIN, Edgar. A via para o futuro da humanidade. Tradução de Edgard de Assis Carvalho e Mariza Perassi Bosco. 2. ed. Rio de Janeiro: Bertrand Brasil, 2015.

ORGANIZAÇÃO DAS NAÇÕES UNIDAS PARA A EDUCAÇÃO, A CIÊNCIA E A CULTURA. Educação para a cidadania global: preparando os alunos para os desafios do século XXI. Brasília: UNESCO, 2015.

ORGANIZAÇÃO DAS NAÇÕES UNIDAS PARA A EDUCAÇÃO, A CIÊNCIA E A CULTURA. Educação para a cidadania global: tópicos e objetivos de aprendizagem. Brasília: UNESCO, 2016a.

ORGANIZAÇÃO DAS NAÇÕES UNIDAS PARA A EDUCAÇÃO, A CIÊNCIA E A CULTURA. Educação para a cidadania global (ECG) - A abordagem da UNESCO. Cartilha. Brasília: UNESCO, 2016b.

POZO, Juan Ignácio. A solução de Problemas: aprender a resolver, resolver para aprender. Porto Alegre: ArtMed, 1998.

ROGERSON, Peter. Métodos estatísticos para a geografia: um guia para o estudante. 7. ed. Porto Alegre: Bookman, 2012.

SHULTZ, Lynette; GUIMARÃES-IOSIF, Ranilce. O impacto de se tornar uma escola associada da UNESCO (PEA) no Brasil. Relatório de Pesquisa. University of Alberta, Edmonton, Canada. Novembro, 2009.

TEIXEIRA, Regina Cleide Figueiredo; TEIXEIRA, Ivani Silva. Jogos de Empresa um Instrumento para o Desenvolvimento Gerencial. ENEGEP, 1998. Disponível em: http://www.abepro.org.br/biblioteca/ENEGEP1998_ART328.pdf. Acesso em: 26 mar. 2017.

TRIOLA, Mário. Introdução à estatística. Rio de Janeiro: LTC, 1999.

UNITED NATION GENERAL ASSEMBLY [UNGA]. Resolutions 58/113 - A and B. 59th Session, Supplement 49. Adopted by the General Assembly on 10 Dec. 2004 and 14 jul. $2005 . \quad$ Disponível em: http://www.un.org/en/ga/search/view_doc.asp?symbol=A/RES/59/113 e $\mathrm{http}: / / w w w . u n . o r g / e n / g a / s e a r c h / v i e w \_d o c . a s p ? s y m b o l=A / R E S / 59 / 113 B$. Acesso em 8 de abril de 2018. 
VALADARES VASCONCELOS Neto, Diego. Aspectos Pedagógicos e Boas Práticas do Concurso Nacional Sistemas Interamericano e Internacional de Direitos Humanos (CNSIDH) da Secretaria de Direitos Humanos da Presidência da República. In: 50 Encontro Nacional da ABRI (Associação Brasileira de Relações Internacionais), 2015, Belo Horizonte. Anais do 50 Encontro Nacional da ABRI, 2015.

VAUS, David A de. Survey in social research. 5. ed. Londres: Routledge, 2002. $379 p$.

Recebido em: 28/04/2018

Aprovado em: 21/09/2018 